\title{
Structural Analysis of Yoke Part in Design of Driveshaft
}

\author{
Onur Şen ${ }^{1 *}$, Mert Can Kahyalar ${ }^{1}$ \\ 0000-0001-8763-3246, 0000-0001-6826-5310
}

${ }^{1}$ Tirsan Kardan Inc., Manisa, 45030, Turkey

\begin{abstract}
Driveshaft used for transmitting torque and rotation, is one of the most important components in motor vehicles. It is required to connect the other components of the drivetrain such as transmission and differential to each other. Basically, a driveshaft comprises of one or more universal joints, yoke parts, splined parts, and sometime center support bearing. Each component on driveshaft is exposed to torsion while they perform their functions such as angular and axial movement. Therefore, each component should be strong enough against to torsion in the design and analysis processes. In this study, numerical and analytical methods were used to design the weld yoke, investigated, and compared with each other. In the numerical studies, finite element analysis (FEA) was implemented by using two different loading conditions respectively force couple and moment. And the strength formulas were used in the scope of analytical method. As a result of the study, the stress on critical section obtained from FEA, supports the results from analytical method. Thus, analytical method can be used for the weld yoke design and the FEA can be implemented by using any of force couple or moment as loading type.
\end{abstract}

Keywords: Analytical method, Designing, Driveshaft, Numerical method; Weld yoke

\author{
* Corresponding author \\ Onur Şen \\ o.sen@tirsankardan.com.tr \\ Tel: +902362330596 \\ Fax: +902362331013 \\ Research Article \\ Manuscript \\ $\begin{array}{ll}\text { Received } & 18.06 .2020 \\ \text { Revised } & 07.08 .2020 \\ \text { Accepted } & 21.09 .2020\end{array}$
}

Adress: MOSB Tirsan Kardan R\&D

Center, Yunusemre, Manisa, Turkey

Doi: 10.30939/ijastech..754821

\section{Introduction}

In a motor vehicle, powertrain covers every component that converts the power from engine into the movement, such as transmission, driveshaft, differential and wheels as seen in Fig. 1. Driveshaft, one of these components of powertrain, is the most important component in motor vehicles, for transmitting torque and rotation. It is used as an intermediate element that provides connection between other components of the drivetrain such as transmission and differential. In this way, it allows for relative movement between them [1].

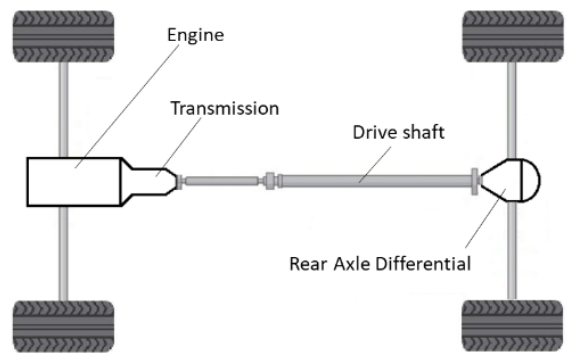

Fig. 1. Powertrain of a motor vehicle.

Driveshaft basically comprises of one or more universal joints, yoke parts, splined parts and center support bearing depending on what the driving and driven components are used. Fig. 2 shows an example of configurations of driveshaft and its sub-components. Each component on the driveshaft performs different functions such as angular and axial movement. All these components, composing the driveshaft, have various geometrical and structural features to perform their basic functions.
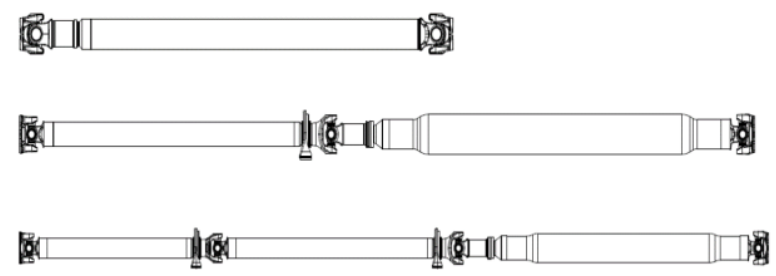

Fig. 2. An example of driveshaft configurations; one piece, two and three pieces in descending order.

Driveshaft therefore its sub-components are subjected to torsion between driving and driven components of the vehicle. Thus, they must be strong enough to withstand the stress 
while having a sufficiently low mass. Although the geometries of driveshaft components are generally within a certain frame, performance improvement and cost reduction studies require some changes in part geometry and material. In this kind of improvement projects, firstly new components are designed or developed in accordance with the design requirement. For the next step, designed 3D models are analyzed and checked by using finite element analysis software. The design and analysis processes are carried out iteratively until a sufficiently strong design is achieved under loading conditions, in terms of Von Mises stress. Finally, the new design is frozen after all these iterative works.

The studies about driveshaft components in literature, mostly universal joint and its sub-parts are investigated in terms of critical stress, failure and loading capacity. K. Živković, et al. (2011) observed how stress change of cross shaft of cardan joint, depending on the changes in its geometry. In the study, the critical stress on the joint cross is calculated and compared with the results from finite element analysis.

Another study handling the universal joint, has been carried out by Farzad Vesali, et al. (2012) in terms of dynamics, especially failure.

A. A. Muley, et al. (2016) observed the failure of slip yoke that is one of the components on the driveshaft. For the other components of the driveshaft such as weld yoke, reverse yoke, a new study is needed.

S. G. Solanke, et al., carried out a study on getting best design of joint with considering the weight, cost, fatigue life, stress distribution, stiffness, etc. FEM and photo elasticity experiment are included in study.

E. Avrigean, et al., analyzed the fatigue characteristics of a driveshaft. In this context, components on the driveshaft including weld yoke are subjected to FEA before fatigue analysis. But not any computational activity on the component there is, for determining the stress.

In another study implemented by V. Kawale, et al., design of driveshaft is investigated considering universal joint and its sub-part, spline characteristic, and connection flange. The study is conducted with only a series of calculations in scope of analytical method. As in the other literature studies mentioned above, in this study too, the weld yoke is not investigated in terms of analytical and numerical analysis.

In this study, numerical and analytical methods for designing weld yoke were investigated and compared with each other. The finite element analysis (FEA), the most widely used method was implemented in the numerical studies, while the strength formulas were used in the calculations performed within the scope of analytical method. As the result of the both methods, the maximum stress on the critical point of the weld yoke, is determined and compared to each other. used comparatively for the design of the weld yoke. Analytical method includes a series of calculations considering the force couple on the weld yoke branches which occurs as the result of the effect of moment from engine. Therefore, finite element analysis in terms of loading was carried out in two different ways, not only by applying moment, but also by applying a force couple. And so, it is possible to make a reliable comparison of the analytical and numerical method results to each other. Additionally, in response to the question "what would happen if moment was applied instead of a force couple?", the analysis in which moment was applied as the loading type, was carried out. As a result, the effect of both loading types (moment and force couple) on the FEA results was compared and discussed.

\subsection{Analytical Method}

Yoke parts are subjected to shearing and bending under torque when the driveshaft transmits the torque through the wheel. Depending on the geometry and material of the yoke part, stress values differ regionally. Therefore, the critical area for each different yoke part is also different. Fig. 3 shows the critical areas in terms of stress, for the various yoke parts.

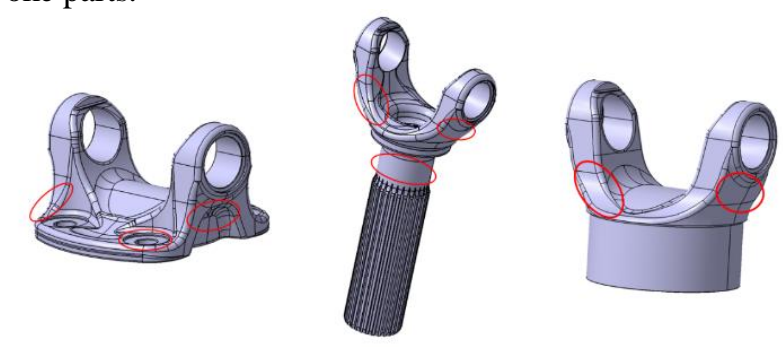

Fig. 3. Critical areas on the yoke parts (respectively; flange yoke, yoke shaft, weld yoke)

In design work, the critical area where the largest stresses occur on the structure, should be taken into consideration. Correspondingly, critical point is selected on the cross section where the stresses reach the largest values. It is possible to determine the critical area for weld yoke, by means of field experiences, finite element analysis, basic strength theories and torsional test simulating the relevant operating conditions.

Furthermore, within those cross sections, the points should be selected where either the normal stresses or the shear stresses have their largest values. Weld yoke is usually broken from the critical cross section including the both areas circled in the Fig. 3. While the critical cross section of the weld yoke is shown in Fig. 4, the critical dimensions on the cross section are given in table 1 .

\section{Methodology}

Principally, two methods, analytic and numerical were 
For the maximum torque value of 4,600 which acts on the
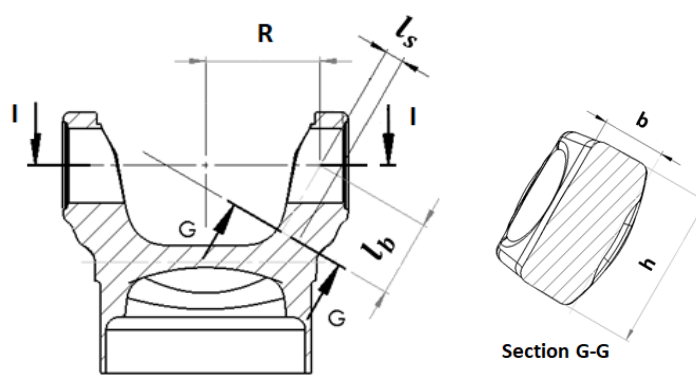

Fig. 4. Critical cross sections of the weld yoke

Table 1. Critical dimensions on the section $\mathrm{G}-\mathrm{G}$

\begin{tabular}{c|c}
$\mathrm{R}(\mathrm{mm})$ & 46.10 \\
\hline $\mathrm{ls}(\mathrm{mm})$ & 7 \\
\hline $\mathrm{lb}(\mathrm{mm})$ & 30.50 \\
\hline $\mathrm{b}(\mathrm{mm})$ & 18.40 \\
\hline $\mathrm{h}(\mathrm{mm})$ & 45.90
\end{tabular}

In addition to keeping the max. stress on the critical section under control, the material selection for weld yoke is another key factor. The properties belonging to steel of C45 grade that is selected for the weld yoke, is shown in Table 2 below.

Table 2. Properties of the weld yoke material - C45

\begin{tabular}{c|c} 
Yield Strength $-\mathrm{Re}(\mathrm{MPa})$ & 370 \\
\hline Ultimate Tensile Strength $-\mathrm{Rm}(\mathrm{MPa})$ & 620 \\
\hline Modulus of Elasticity $-\mathrm{E}(\mathrm{GPa})$ & 210 \\
\hline Poisson's Ratio $-\mathrm{v}$ & 0.3 \\
\hline Density $\left(\mathrm{gr} / \mathrm{cm}^{3}\right)$ & 7.85
\end{tabular}

Maximum force on the branch of the weld yoke,

Considering the weld yoke on the driveshaft alone, force couple produced by the torque acting on it, is shown in Fig. 5 below.

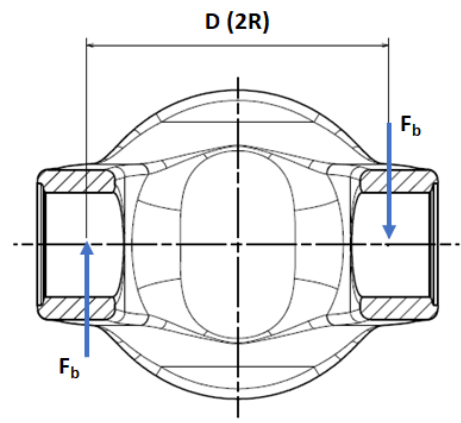

Section I-I

Fig. 5. Force couple on the branch of the weld yoke weld yoke, the maximum force on the branch of the weld yoke, shown in Fig. 5, can be calculated by fallowing equation.

$T=F_{b} . D=F_{b} .2 R$

$F_{b}=49.89 \mathrm{~N}$

where " $\mathrm{T}$ " is the maximum torque acting on the weld yoke, " $\mathrm{Fb}$ " is the force on one branch of the weld yoke and D is the distance of the force action points on the each branch of the weld yoke, and " $\mathrm{R}$ " is the effective radius.

The force on the branch, calculated above causes bending and shearing on the critical section. To calculate the bending stress on the critical section, respectively bending moment, and moment of inertia according to critical section, can be determined in following form.

$M_{B}=F_{b} \cdot l_{b}$

$M_{B}=1,522$

where " $\mathrm{M}_{\mathrm{B}}$ " is the bending moment and " $l_{b}$ " is the lever arm for the bending,

$I=\frac{b \cdot h^{3}}{12}$

$I=1.48 \quad 10^{-7} \mathrm{~m}^{4}$

where "I" is moment of inertia of a solid having rectangular section, "b" and " $h$ " is the dimension of the critical section (G-G). The section is considered as rectangular shape having "b" and " $h$ " as in the Fig. 4.

As a result of the equation below, the bending stress is:

$\sigma_{b}=\frac{M_{B} \cdot c}{I}$

$\sigma_{b}=235.52 \mathrm{MPa}$

where " $\sigma b$ " is bending stress and "c" is the distance from neutral surface to outside edge $(\mathrm{c}=\mathrm{h} / 2)$.

To calculate the shear stress on the critical section, respectively torsional moment, and polar moment of inertia according to the critical section, can be determined in following form.

$M_{T}=F_{b} \cdot l_{s}$

$M_{T}=349.24$ 
Where " $M_{T}$ " is the torsional moment and " $l_{S}$ " is the lever arm for the shear,

$\mathrm{J}=\frac{b \cdot h \cdot\left(h^{2}+b^{2}\right)}{12}$

$\mathrm{J}=1.721110^{-7} \mathrm{~m}^{4}$

where "J" is polar moment of inertia according to a solid having rectangular section " $b$ " and " $h$ ", the dimension of the critical section (G-G). The section is considered as rectangular shape having " $b$ " and " $h$ " as in the Fig. 4.

As a result of the equation below, where " $r$ " is the distance from neutral surface to outside edge $(\mathrm{r}=\mathrm{b} / 2)$, the shear stress is:

$\tau=\frac{M_{T} \cdot r}{j}$

\section{$\tau=18.67 \mathrm{MPa}$}

Mostly used equivalent stress is based on Von Mises yield criterion. The Von Mises stress is used to determine whether yielding occurs on the component with isotropic and ductile material when they are under complex loading conditions. Equivalent stress depending on Von Mises and considering bending and torsion, can be calculated by using the following equation [8].

$\sigma_{e}=\sqrt{\sigma_{b}^{2}+3 \cdot \tau^{2}}$

$\sigma_{e}=237.73 \mathrm{MPa}$

\subsection{Finite Element Analysis}

The analysis was carried out as linear static structural under steady state conditions using FEM by applying the boundary conditions. As a result of the FEA, distribution of Von Mises stress was obtained.

In the FEA studies firstly, weld yoke designed in 3D CAD software was imported to HyperWorks CAE software. In pre-processing, the geometry of the weld yoke was modified and prepared for meshing process. Meshing process has been started by using R-tria elements with size of $0.8 \mathrm{~mm}$. The result of 2D meshing, shell elements has been checked and modified to achieve a good quality of mesh. After this phase, 3D mesh structure was created with first-order tetra 3D elements. After 3D meshing, totally 1,068,883 elements and 231,534 nodes were generated.

As mentioned in the introduction, two different analysis were carried out in terms of load condition, respectively force couple and pure moment.

Boundary conditions for the analysis with loading by force couple:

1D rigid element has been created inside of each yoke holes as shown in Fig. 6. The force of 49,758 N corresponding to the moment acting on the yoke, has been defined on the nodes of the rigid structures on each yoke's hole and in the opposite direction as shown in Fig. 6. The definition of constraint has been applied to the nodes of rigid structures in the direction of force and rotation axis, which gives freedom in rotation and translation. For the lower side of the weld yoke where the welding operation is performed, as shown in Fig. 6, the constraint has been defined in a way that does not allow rotation and translation in all axes by using rigid elements. Elasticity modulus of $210 \mathrm{GPa}$ and Poisson's ratio of 0.3 have been used as input data for the material of weld yoke.

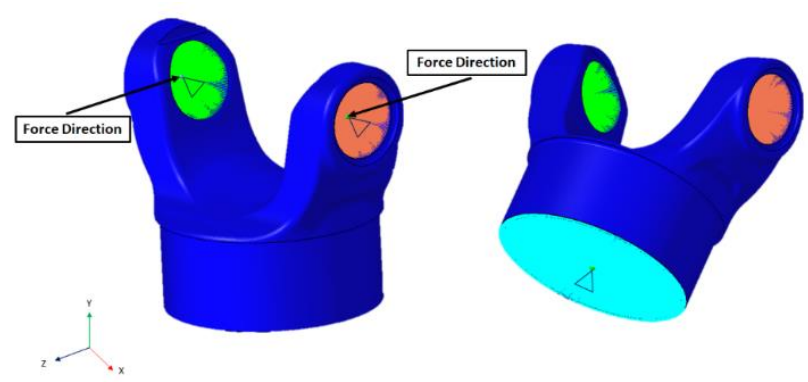

Fig. 6. Boundary conditions for the analysis with loading by force couple

Boundary conditions for the analysis with loading by moment:

Rigid elements have been created on each yoke branches. And so the moment acting on the weld yoke is distributed equally as shown in Fig. 7.

The torque of 4,600 is defined in the middle node of the rigid structure. At the same time, constraint which gives freedom of rotation and translation in the axis of rotation, has been applied on the node of rigid structure. For the lower side of the weld yoke where the welding operation is preformed, as shown in Fig. 7, the constraint has been defined in a way that does not allow rotation and translation in all axes by using rigid elements. Elasticity modulus of $210 \mathrm{GPa}$ and Poisson's ratio of 0.3 have been used as input data for the material of weld yoke.
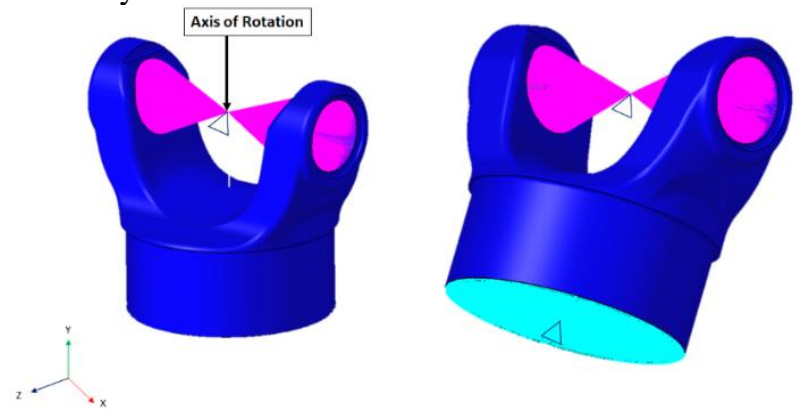

Fig. 7. Boundary conditions for the analysis with loading by moment

After the defining load and constraints, the solution process has been implemented by linear static structural method. In solution process OptiStruct has been used as solver. 


\section{Results of FEA}

Von Mises stress value on the critical area (Fig. 3 and Fig. 4) which is taken into consideration for the theoretical calculations, has been obtained as $241 \mathrm{MPa}$ for the loading type of force couple, while $240 \mathrm{MPa}$ has been obtained for the loading type of moment as shown Fig. 8. The stress on the lower side of the weld yoke where the welding operation is performed, has been ignored because they occur due to lack of freedom.
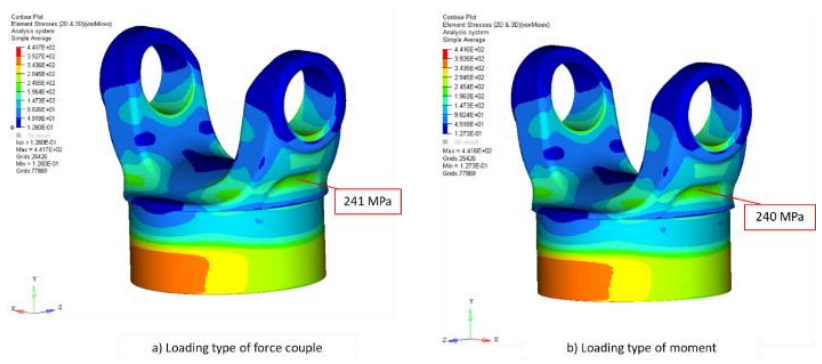

Fig. 8. Von Mises stress on the critical section, respectively for the loading type of force couple and for the loading type of moment

Equivalent stress via Von Mises was calculated to include bending and shear stresses on the critical area. By this way, equivalent stress obtained as $237.73 \mathrm{MPa}$.

\section{Conclusions}

In this study, for the design of weld yoke, finite element analysis and analytical method are carried out. The result of $241 \mathrm{MPa}$ from the finite element analysis including loading type of force couple, is highly closed to the result of $240 \mathrm{MPa}$ from the finite element analysis including loading type of moment. When considering the analytical studies, the results from finite element analysis and the results from analytical method, are similar to each other with a deviation approximately equal to $3 \mathrm{MPa}$. These results reveal that,

- Stress values of critical section obtained from FEA, supports the results from analytical method. Thus, analytical method can be used for the weld yoke design.

- In the FEA, any of force couple or moment can be used as loading type. Because, the results from the studies where the both loading types are used are as close to each other as acceptable level.

- Maximum stress on the critical area of the weld yoke is determined lower than the yield strength of the material. In other words, there is no plastic deformation on the weld yoke. Thus, design of the weld yoke was frozen.

- Similar studies can be implemented for the design of the rest components on drive shaft; due to each component on the driveshaft have different geometry and material.

\section{Acknowledgment}

This study has been carried out in Tirsan Kardan R\&D Center.

\section{Nomenclature}

$T \quad$ : max. torque acting on the weld yoke $(\mathrm{Nm})$

$F_{b}$ : the force on one branch of the weld yoke $(\mathrm{N})$

$D$ : the distance of the force action points on the each branch of the weld yoke (mm)

$R \quad$ : effective radius $(\mathrm{mm})$

$M_{B}$ : bending moment $(\mathrm{Nm})$

$l_{b}$ : the lever arm for the bending (mm)

I : moment of inertia of a solid having rectangular section $\left(\mathrm{m}^{4}\right)$

$\mathrm{b}$ : the dimension of the critical section G-G (mm)

$\mathrm{h}$ : the dimension of the critical section G-G (mm)

$\sigma_{b} \quad$ : bending stress (MPa)

$\mathrm{c}$ : the distance from neutral surface to outside edge $(\mathrm{mm})$

$M_{T} \quad$ : torsional moment $(\mathrm{Nm})$

$l_{s}:$ the lever arm for the shear (mm)

$\mathrm{J} \quad$ : polar moment of inertia according to solid having rectangular section $\left(\mathrm{m}^{4}\right)$

$\mathrm{r}$ : the distance from neutral surface to outside edge $(\mathrm{mm})$

$\sigma_{e} \quad$ : equivalent stress $(\mathrm{MPa})$

\section{References}

[1] Seherr-Thoss, H.Chr., Schmelz, F., Aucktor, E. (2006). Universal Joints and Drive shafts, Chapter 1.

[2] Živković, K., Ivanović, L., Stojanović, B. (2011). The effect of geometry on the stress distribution of cross shaft. IRMES International Scientific Conference.

[3] Vesali, F., Rezvani, M. A., Kashfi, M. (2012). Dynamics of universal joints, its failures and some propositions for practically improving its performance and life expectancy. Journal of Mechanical Science and Technology, 2439-2449.

[4] Muley, A. A., Sheikh, M. J. (2016). Design and analysis of yoke joint assembly. International Journal of Engineering Research \& Technology.

[5] Solanke, S. G., Bharule, A. S. (2014) .An investigation on stress distribution for optimization of yoke in universal joint under variable torque condition. International Journal of Mechanical Engineering and Robotics Research. Vol. 3, 2.

[6] Avrigean, E. (2014). Determining the fatigue characteristics of the vehicle cardanic joint. International Journal of Science and Research, Volume 3.

[7] Kawale, V., Patil, G., Pune, S. (2018). Design methodology of drive shaft. International Journal of Advance Research in Science and Engineering. Vol. 07.

[8] Dumitru, I., Kun, L., Dreucean, M., Menyhardt, K. (2011). The equivalent stress concept in multiaxial fatigue. Journal of Engineering Studies and Research. Volume 17, No. 2.

[9] Heisler, H. (2002). Advanced Vehicle Technology. 